\title{
Structural and Mechanical Properties of Alumina-Zirconia (ZTA) Composites with Unstabilized Zirconia Modulation
}

\author{
Md. Abdul Gafur1, Md. Al-Amin"1,2, Md. Saifur Rahman Sarker3, Md. Zahangir Alam² \\ ${ }^{1}$ Pilot Plant \& Process Development Centre, Bangladesh Council of Scientific and Industrial Research, Dhaka, Bangladesh \\ ${ }^{2}$ Department of Applied Chemistry and Chemical Engineering, Dhaka University, Dhaka, Bangladesh \\ ${ }^{3}$ Kurigram Govt. College, Kurigram, Rangpur, Bangladesh \\ Email: d_r_magafur@yahoo.com
}

How to cite this paper: Gafur, Md.A., Al-Amin, Md., Sarker, Md.S.R. and Alam, Md.Z. (2021) Structural and Mechanical Properties of Alumina-Zirconia (ZTA) Composites with Unstabilized Zirconia Modulation. Materials Sciences and Applications, 12, 542-560.

https://doi.org/10.4236/msa.2021.1211036

Received: September 10, 2021

Accepted: November 22, 2021

Published: November 25, 2021

Copyright $\odot 2021$ by author(s) and Scientific Research Publishing Inc. This work is licensed under the Creative Commons Attribution International License (CC BY 4.0).

http://creativecommons.org/licenses/by/4.0/

(c) (i) Open Access

\begin{abstract}
Zirconia toughened alumina (ZTA) ceramics are very promising materials for structural and biomedical applications due to their high hardness, fracture toughness, strength, corrosion and abrasion resistance and excellent biocompatibility. The effect of unstabilized $\mathrm{ZrO}_{2}$ on the density, fracture toughness, microhardness, flexural strength and microstructure of some Zirconia-toughened alumina (ZTA) samples was investigated in this work. The volume percentage of unstabilized $\mathrm{ZrO}_{2}$ was varied from $0 \%-20 \%$ whereas sintering time and sintering temperature were kept constant at 2 hours and $1580^{\circ} \mathrm{C}$. The samples were fabricated from nanometer-sized $\left(\alpha-\mathrm{Al}_{2} \mathrm{O}_{3}: 150 \mathrm{~nm}\right.$, monoclinic $\mathrm{ZrO}_{2}: 30$ - $60 \mathrm{~nm}$ ) powder raw materials by the conventional mechanical mixing process. Using a small amount of sintering aid (0.2 wt\% $\mathrm{MgO})$ almost $99.2 \%$ of theoretical density, 8.54 $\mathrm{MPam}^{1 / 2}$ fracture toughness, $17.35 \mathrm{GPa}$ Vickers microhardness and 495.67 $\mathrm{MPa}$ flexural strength were found. It was observed that the maximum flexural strength and fracture toughness was obtained for 10 vol\% monoclinic $\mathrm{ZrO}_{2}$ but maximum Vickers microhardness was achieved for $5 \mathrm{vol} \% \mathrm{ZrO}_{2}$ although the maximum density was found for 20 vol\% $\mathrm{ZrO}_{2}$. It is assumed that this was happened due to addition of denser component, phase transformation of monoclinic $\mathrm{ZrO}_{2}$ and the changes of grain size of $\alpha-\mathrm{Al}_{2} \mathrm{O}_{3}$ and $\mathrm{ZrO}_{2}$.
\end{abstract}

\section{Keywords}

Zirconia Toughened Alumina (ZTA), Mechanical Properties, Toughening, XRD, SEM, Grain Size 


\section{Introduction}

All materials can be broadly classified into three categories: Metal, Ceramic and Polymer. For the better high temperature strength, light weight, low wear rate and high hardness properties make ceramic the material of choice for a wide range of applications [1]. Alumina is one of the most extensively used and cost-effective materials in engineering ceramic family. It is one of the hardest materials and its hardness is just only next to diamond ( 9 out of 10 in Mohs scale). It has strong ionic interatomic bonding that provides its reputed material features. Several inherent properties such as low thermal conductivity, comparatively high thermal expansion coefficient and pronounced chemical stability make it appropriate to choose for ceramic materials. In the early 70s' bio-ceramics were employed to perform singular biologically inert roles, such as to provide parts for bone replacement. Alumina $\left(\mathrm{Al}_{2} \mathrm{O}_{3}\right)$ as an inert bio-ceramic has also biomedical application as an alternative to metal alloys for the replacement of hip prostheses and dental implants. However, the low fracture toughness property limits its load-bearing capacity which is the major drawback of it [2]. Like alumina, zirconia is also one of the most versatile of refractory ceramic oxide. An excellent corrosion resistance, strength, toughness and chemical inertness properties make it superior for the ceramic composites at temperature well above the melting temperature of alumina. It needs to be stabilized for avoid cracking under stress conditions. It has three polymorphs: monoclinic (m, up to $1170^{\circ} \mathrm{C}$ ), tetragonal (t, up to $2370^{\circ} \mathrm{C}$ ) and cubic (c, up to $2680^{\circ} \mathrm{C}$ ) [3]. With increasing heating temperature, phases transform from monoclinic to tetragonal zirconia associated with almost $5 \%$ volume change [4] [5] [6]. During cooling to room temperature, tetragonal phase of zirconia transforms into monoclinic phase with expansion of its volume of nearly $3 \%-5 \%$. If any stress is applied, the stabilized tetragonal phases of zirconia at room temperature change their phases into monoclinic with expanding their volume by absorbing the energy applied on them and stop the crack to propagate further which is referred to as stress-induced phase transformation of zirconia [7]. Through applying this phase transformation mechanism, it increases the fracture toughness of the composite materials that are generally defined as the toughening mechanism. To retain in tetragonal phase at room temperature, the grain size of zirconia must be smaller than the critical transformation size, below which no phase transformation occurs [8]. Relative distribution of $\mathrm{ZrO}_{2}$ and volume fraction of $\mathrm{ZrO}_{2}$ retained in the metastable tetragonal phase are also responsible for the increases of fracture toughness of the composites. Finer particle size enhances the uniform distribution of both $\mathrm{Al}_{2} \mathrm{O}_{3}$ and $\mathrm{ZrO}_{2}$ particles and tetragonal phase retention possibilities of $\mathrm{ZrO}_{2}$ particle [9]. On the other hand, in the case of over-stabilization, the stress required for the phase transformation may be higher than the fracture toughness. That's why the fracture toughness will be reduced. So, no stabilizer is used in this experimental procedure. Side by side increases the volume percentages of $\mathrm{ZrO}_{2}$ also decreases the percentages of tetragonal $\mathrm{ZrO}_{2}$ retention. So, an optimum amount $\mathrm{ZrO}_{2}$ ad- 
dition is required for getting the maximum desired properties. Previous research found that the mixture of both monoclinic and tetragonal phases of $\mathrm{ZrO}_{2}$ has provided the maximum fracture toughness in zirconia toughened alumina (ZTA) [10].

To overcome the shortcomings of alumina ceramics, Alumina-Zirconia (AZ) ceramic composites are extensively explored over the last two decades [11] [12]. Among these composites, zirconia toughened alumina (ZTA) has been elaborately studied due to its prominent mechanical properties such as high corrosion resistance and chemical stability. Alumina has high hardness and the toughness of the zirconia is very good. Zirconia toughened alumina (ZTA) composite ceramics have the properties of both materials. The performance of zirconia toughened alumina ceramics is much better than the alumina ceramics and the price is much lower than the zirconia ceramics. Upgraded mechanical properties would be found by the incorporation and more homogeneous distribution of zirconia in alumina matrix [13] [14] [15] [16]. According to application purposes, properties of the ceramics can be tailored to depend on the percentage of the contents. Due to superior mechanical behavior it may be used in both biomedi$\mathrm{cal}$ and engineering applications. The addition of sintering aid $(\mathrm{MgO}, \mathrm{CaO})$ as a small amount increases the densification process of the Alumina-Zirconia ceramic composites by lowering the sintering temperature as well as decreases the grain growth of Alumina resulting in a stronger composite formed.

The previous studies emphasized the improvement of mechanical properties of ZTA by using stabilized zirconia as reinforcement [17] [18]. The analysis also reported that stabilized zirconia has a great effect (impart toughening mechanism) on the mechanical properties. But the effect of unstabilized zirconia on the properties of ZTA is not extensively studied particularly using the powder compaction method. In this investigation, optimization of the composition will be done to get maximum fracture toughness, microhardness, flexural strength and density by varying the volume percentage of unstabilized zirconia. To get the proper output conventional powder compaction method is applied for the sample preparation. Absolute ethanol is used as a liquid media for uniform mixing of the raw powders during pot milling. A sintering schedule will be followed for all composition of the sample by keeping sintering time and temperature at constant level. That will be an alternative and convenient approach to produce Alumina-Zirconia $\left(\mathrm{Al}_{2} \mathrm{O}_{3}-\mathrm{ZrO}_{2}\right)$ ceramic composites which might be used in replace of other traditional ceramic composites rather than cost effectively.

\section{Materials}

Commercially available ceramic powders such as nanocrystalline alpha-alumina powder (purity $99.9 \%$, average particle size $\sim 150 \mathrm{~nm}$, Advance materials, USA), monoclinic zirconia powder (purity 99.9\%, particle size $30-60 \mathrm{~nm}$, Advanced materials, USA) and magnesiumoxide (purity $>97 \%$, particle size $<50 \mathrm{~nm}$, RCL Labean Ltd., Thailand) were taken for this work. Here high purity alumina was used as a base material due to avoid the formation of glassy phases on the grain 
boundaries of ceramic composites. Unstabilized zirconia was incorporated rather than partially stabilized zirconia (PSZ) as it limits the activity of transformation during crack propagation. Different volume percentages of monoclinic zirconia (such as $0,2,5,10,15$ and $20 \mathrm{vol} \%$ ) and $0.2 \mathrm{wt} \%$ of $\mathrm{MgO}$ were added to alumina for the fabrication of ceramic materials.

\section{Methodology}

Initially right amount of powder raw materials is taken into a polypropylene pot. Absolute ethanol (Merck, Germany) is used as a solvent media for wet milling. For the homogeneous mixing of the powders 24 hours pot milling is continued by motor driven mill with yttria stabilized zirconia balls as a grinding media. Then the mixture was dried in a vacuum oven (UE600, Memmert, Germany) at $100^{\circ} \mathrm{C}$ for 24 hours. The dried mixture was milled in a mortar pestle for more uniform mixing and 5\% PVA (polyvinyl alcohol) solution was added as a binder for providing green strength of the samples. After that the blended mixture was unidirectionally pressed in discs (10 mm diameter) at $210 \mathrm{MPa}$ for $120 \mathrm{sec}$ using UTM (FS 300 kN, Testometric Co. Ltd., England). Before sintering in a high temperature heating furnace (BPAN-2010, Micropyretics Heaters International, USA) at $1580^{\circ} \mathrm{C}$ for 2 hours at the heating rate of $5^{\circ} \mathrm{C} / \mathrm{min}$ in a pressure less condition, the green samples were dried at $100^{\circ} \mathrm{C}$ for 24 hours in an oven (UE600, Memmert, Germany) for the removal of the containing moisture. During sintering there was maintained a holding period of time (3 hours) at $600^{\circ} \mathrm{C}$ for the complete removal of binder from the sample. The cooling rate of the sample from the sintering temperature was comparatively higher $\left(10^{\circ} \mathrm{C} / \mathrm{min}\right)$. Single stage sintering cycle of this work is shown in Figure 1.

The density of the sintered body was measured by immersion in distilled water using Archimedes' principle. At least six samples were considered for density determination of any type of sintered sample and the variation in the density

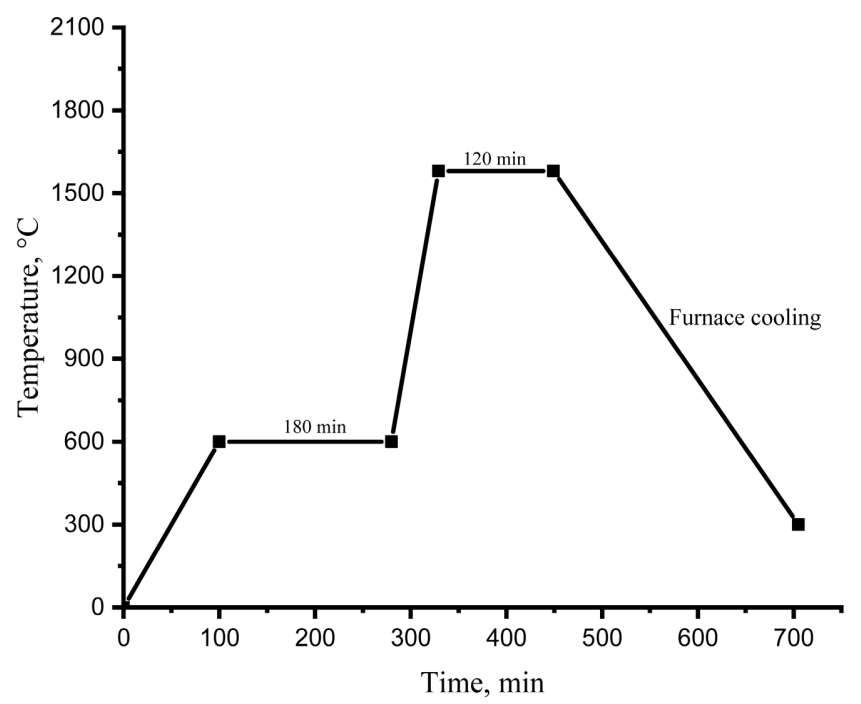

Figure 1. Typical sintering cycle. 
was shown to be within $\pm 1 \%$. Standard Archimedes formula for calculating the density of the sintered sample is as follows:

$$
\rho_{s}=\frac{m_{s} \rho_{w}}{m_{s}-m_{w}}
$$

where, $\rho_{s}$ is the density of the sintered sample, $\rho_{w}$ is the density of the water, $m_{s}$ is the mass of the sintered disc, $m_{w}$ is the mass of the disc in water.

The percentage of total porosity $\varphi$ was calculated from the sintered density and the theoretical density $\rho_{0}$ according to the standard formula [19]:

$$
\varphi=\left(1-\frac{\rho}{\rho_{\mathrm{o}}}\right) \times 100
$$

where, $\varphi$ is the total porosity of the sample, $\rho$ is density of sintered pellet and $\rho_{0}$ is the theoretical density for samples.

The microhardness was determined on the polished surface of sintered sample by using microhardness tester (HMV-2 Series, Shimadzu Corporation, Japan) following Vickers indentation approach. This value was measured from the ratio of the applied load to the area of the contact of four faces of the undeformed indenter. Following formula was applied to compute Vickers hardness:

$$
H_{v}=0.0018544\left(\frac{P}{d^{2}}\right)
$$

where, $H_{V}$ is the Vickers hardness $(\mathrm{GPa}), P$ is the applied load $(\mathrm{N}), d$ is the average length of two diagonals of the indentations ( $\mathrm{mm})$.

The porosity dependence Elastic Modulus can also be measured using Dewey-Mackenzie relation [20]:

$$
E=E_{o}(1-2 \varphi)
$$

where, $E$ is the effective elastic modulus of porous composites. $E_{o}$ is the elastic modulus of the dense composite and $\varphi$ is the porosity of the sample.

Fracture toughness of the composite was measured on the polished surface of the sintered composite by Vickers indentation fracture methodusing the followingAnstis equation [21]:

$$
K_{I C}=0.016\left(\frac{E}{H_{v}}\right)^{1 / 2}\left(\frac{P}{C^{\frac{3}{2}}}\right)
$$

where, $K_{I O}, H_{r}, E, P$ and $C$ stand for the fracture toughness (MPam ${ }^{1 / 2}$ ), Vickers hardness $(\mathrm{GPa})$, elastic modulus $(\mathrm{GPa})$, indentation load $(\mathrm{MN})$ and radial crack length $(\mathrm{m})$, respectively. In this case applied load was $20 \mathrm{~kg}$ for 15 second (DVK-2, MATSUZAWA). All fracture surfaces were observed in an optical microscope (NMM-800T RF, USA). Before indentation the specimen surface was ground successively using 1200 and 4000 grit SiC discs respectively. Following this, the samples were polished in $6 \mu \mathrm{m}$ and $1 \mathrm{~m}$ diamond paste on a texmet cloth. The reported values were the average of data obtained from six indentation tests. 
Crystalline Phases identification was performed on sintered surface by using X-ray diffractometer (XRD) with CuK $\alpha$ radiation $(\lambda=1.54 \AA$ ) (D8 Advance, BRUKER, Germany) technique. The scanning speed was $2 \%$ min and range of the $2 \theta$ value was $20^{\circ}-70^{\circ}$. The volume fraction of monoclinic zirconia $\left(V_{m}\right)$ was calculated according to the following equation [22].

$$
V_{m}=\frac{I_{\left(\overline{(111)_{m}}\right.}+I_{(11)_{m}}}{I_{(\overline{1} 11)_{m}}+I_{(111)_{m}}+I_{(11)_{t}}}
$$

where, $I$ is the integral intensity and the subscripts $m$ and $t$ refer to the monoclinic and tetragonal phase, respectively.

Microstructure of the sample was studied by Scanning Electron Microscopy (SEM). The polished samples were sputter coated with platinum coating in a sputtering for $2-3$ minutes to make the surface conducting. The specimens were observed by SEM (JEOL-6490, Japan) in secondary electron (SE) mode at $20 \mathrm{KV}$ accelerating voltage. The average grain sizes of alumina and zirconia were measured from the microstructure by using line intercept method. Thermodynamically stable $\mathrm{m}-\mathrm{ZrO}_{2}$ and the retention of $\mathrm{t}-\mathrm{ZrO}_{2}$ phases were studied following Garvie's method [23].

\section{Results and Discussion}

\subsection{Density and Porosity}

The following Figure 2 and Figure 3 indicate the variation of the density and porosity of sintered composites as a function of the vol\% of zirconia content. The reported values are the average of data found from six pellets. It has been seen that the density of the sintered body increases with increasing zirconia contentand the porosity decreases with increasing zirconia. This is due to the addition of denser zirconia $\left(5.68 \mathrm{~g} / \mathrm{cm}^{3}\right)$ into the alumina $\left(3.97 \mathrm{~g} / \mathrm{cm}^{3}\right)$ matrix. For the addition of 0 vol\% of $\mathrm{ZrO}_{2}$ to $\mathrm{Al}_{2} \mathrm{O}_{3}$ matrix, the density of the sample was

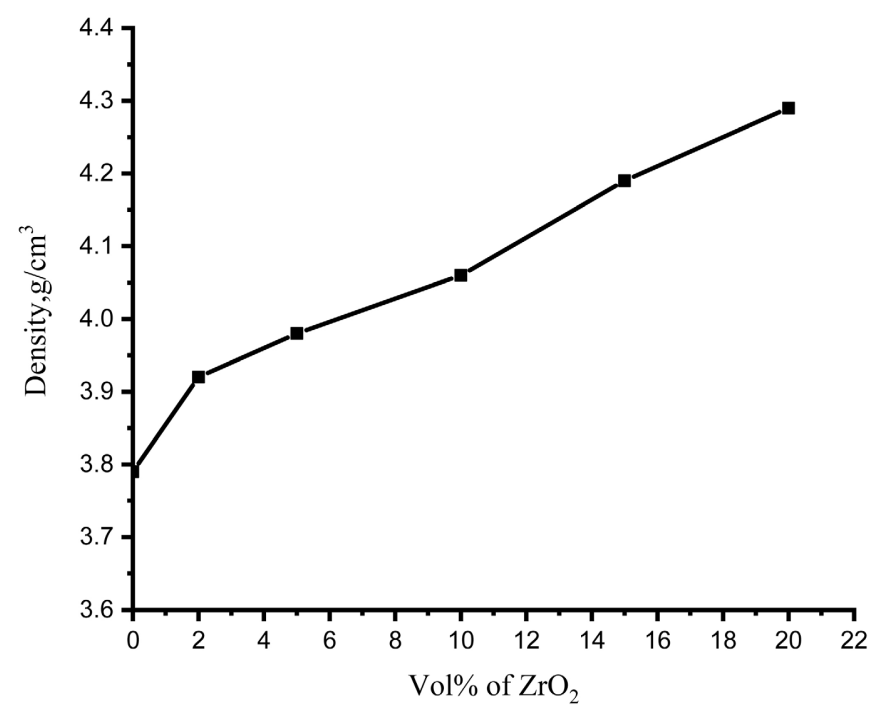

Figure 2. Effect of $\mathrm{ZrO}_{2}$ addition on the density of the $\mathrm{Al}_{2} \mathrm{O}_{3}-\mathrm{ZrO}_{2}$ composites. 


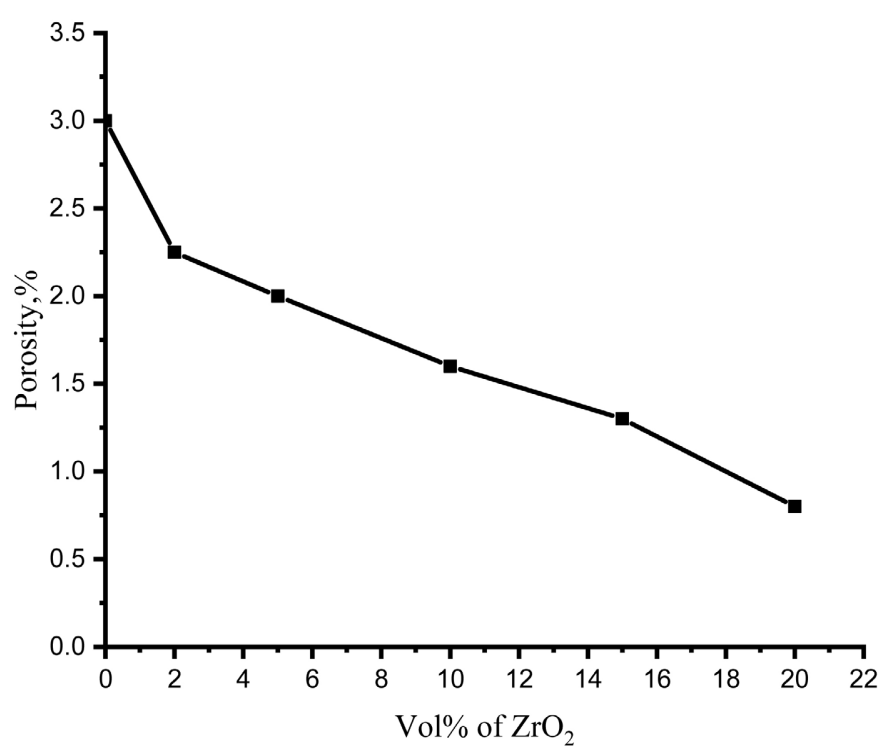

Figure 3. Effect of $\mathrm{ZrO}_{2}$ addition on the porosity of the $\mathrm{Al}_{2} \mathrm{O}_{3}-\mathrm{ZrO}_{2}$ composites.

found $97.2 \%$ of the theoretical density whereas the density increased to $99.2 \%$ of the theoretical density in case of $20 \mathrm{vol} \% \mathrm{ZrO}_{2}$ addition. The percentage of porosity is $2.8 \%$ for pure alumina but for the addition of $20 \mathrm{vol} \% \mathrm{ZrO}_{2}$ in alumina matrix, it reduced to $0.8 \%$ due to removal of pores from the composites. That means, highly dense and less porous structured was formed when $20 \mathrm{vol} \%$ of $\mathrm{ZrO}_{2}$ was incorporated in alumina matrix which could be sintered at $1580^{\circ} \mathrm{C}$ for 2 hours. This density and porosity values conform to some previous research works that has been done by pressureless sintering techniques [24] [25]. Generally, it is well known that, the highest denser and the lowest porous composites provide better mechanical properties. Density also depends on the tetragonal phase retention of $\mathrm{ZrO}_{2}$ in strong alumina matrix around, as the volume of tetragonal phase is lower ( 5\%) than the monoclinic phase of $\mathrm{ZrO}_{2}$. So, less the $\mathrm{t}-\mathrm{ZrO}_{2}$ phase content results the highest densification of the composites. It is observed from XRD data that, composite containing $20 \mathrm{vol} \%$ of $\mathrm{ZrO}_{2}$ provides the lowest (10.4\%) content oft- $\mathrm{ZrO}_{2}$ phases whereas the highest $(\sim 70 \%) \mathrm{t}-\mathrm{ZrO}_{2}$ phases was found for the content of $5 \mathrm{vol} \% \mathrm{ZrO}_{2}$. From the grain size analysis of sintered sample, it was found that, initially the grain size of $\mathrm{Al}_{2} \mathrm{O}_{3}$ decreased significantly with increasing vol\% of $\mathrm{ZrO}_{2}$ content and further addition led to decrease the grain size slowly. Finer grain size is more expected for the homogeneous distribution of the particles results in the increase in density. So, grain size of $\mathrm{Al}_{2} \mathrm{O}_{3}$ matrix was found minimum for $20 \mathrm{vol} \% \mathrm{ZrO}_{2}$ content into it and maximum for pure $\mathrm{Al}_{2} \mathrm{O}_{3}$.

\subsection{Vickers Microhardness $\left(H_{v}\right)$ and Elastic Modulus $(E)$}

Vickers microhardness of sintered studied materials as a function of vol\% of zirconia is shown in Figure 4. This property may be described on the basis of porosity and grain size. 


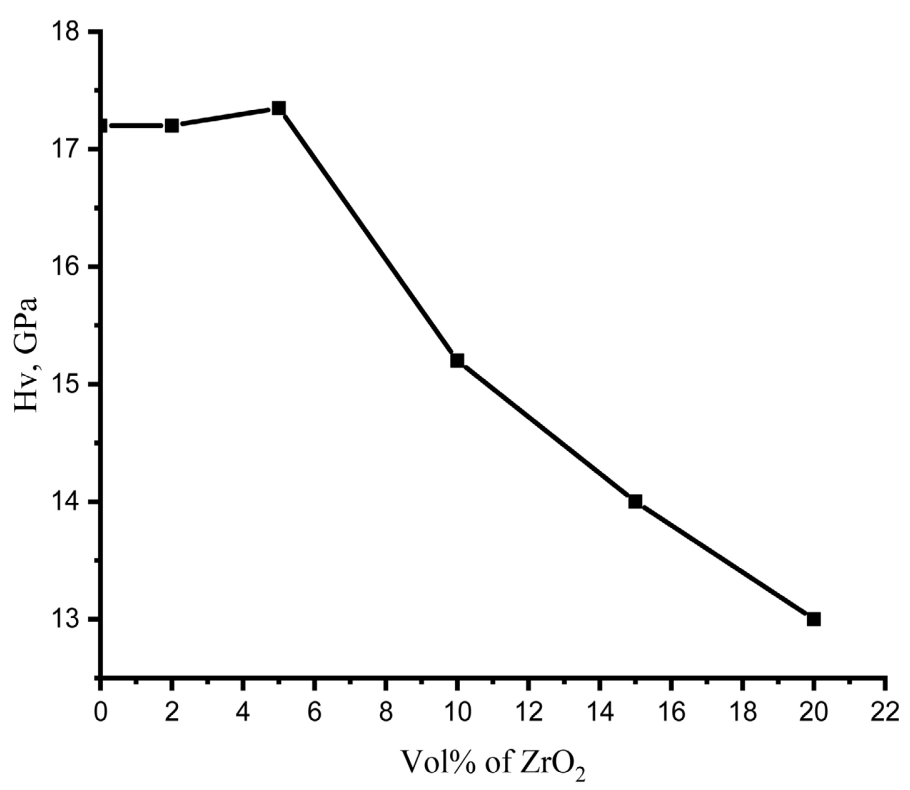

Figure 4. Effect of $\mathrm{ZrO}_{2}$ content on hardness of the Alumina-Zirconia composites.

From the Figure 4, it is observed that, the hardness of the ZTA composite decreases $(17.2$ to $12.98 \mathrm{GPa})$ with the addition of zirconia though initially it is increased $(17.35 \mathrm{GPa})$ slightly with zirconia content up to 5 vol\%. As zirconia has lower hardness than the alumina. So, there will be general tendency of decreasing in hardness with increasing zirconia content. From the SEM analysis it was observed that grain size of alumina decreased with the addition of zirconia but this rate was very significant in case of lower content of zirconia up to 5 vol\% after that it was almost linear. On the other hand, the grain size of zirconia is increased $(0.35-0.48 \mu \mathrm{m})$ from lower to higher amount of addition into the alumina matrix. Due to the coarsening of zirconia grains and the formation of subsequent porosity in the ZTA composite, the hardness of the sintered materials will be decreased with higher amount of zirconia. But for $5 \mathrm{vol} \% \mathrm{ZrO}_{2}$, the lower content of zirconia (hardness also lower than alumina) and abrupt grain size decreased of alumina results the maximum hardness $(17.35 \mathrm{GPa})$ of the studied materials. It has been noticed that, the average grain size has significant impact on microhardness value.

Elastic modulus of the sintered ZTA samples at different concentration of zirconia is represented in Figure 5. Elastic modulus of the composite depends on the volume fraction of the components present in it and their individual modulus of elasticities [26]. As alumina has a higher modulus of elasticity $(347.58 \mathrm{GPa})$ than zirconia (199 $\pm 2 \mathrm{GPa})$ [27]. So, the sample containing 2 vol\% $\mathrm{ZrO}_{2}$ has the maximum modulus of elasticity (350.1 GPa) and minimum modulus of elasticity $(330.56 \mathrm{GPa})$ for the sample containing the highest amount of zirconia (20 vol\% of $\mathrm{ZrO}_{2}$ ). The increase of the grain size of zirconia and decrease of the grain size of alumina also contributes the lowering of elastic modulus of ZTA composites. 


\subsection{Flexural Strength and Fracture Toughness}

The flexural strength and fracture toughness of the ZTA composite at different zirconia content are presented in Figure 6 and Figure 7 respectively.

It has been shown from Figure 6 and Figure 7 that, the flexural strength as well as fracture toughness of composite increases linearly with increase of zirconia addition up to 10 vol\%, then decreased. This is due to the grain size of zirconia increases linearly with increasing zirconia content. An increase in grain size improves the possibilities of phase transformation (tetragonal to monoclinic), as a result increasing strength and toughness. For pure alumina maximum flexural strength was obtained 425.23 $\mathrm{MPa}$ and maximum fracture toughness was obtained $3.95 \mathrm{MPam}^{1 / 2}$. For composite containing unstabilised zirconia maximum flexural strength $(495.8 \mathrm{MPa})$ and maximum fracture toughness $\left(8.54 \mathrm{MPam}^{1 / 2}\right)$

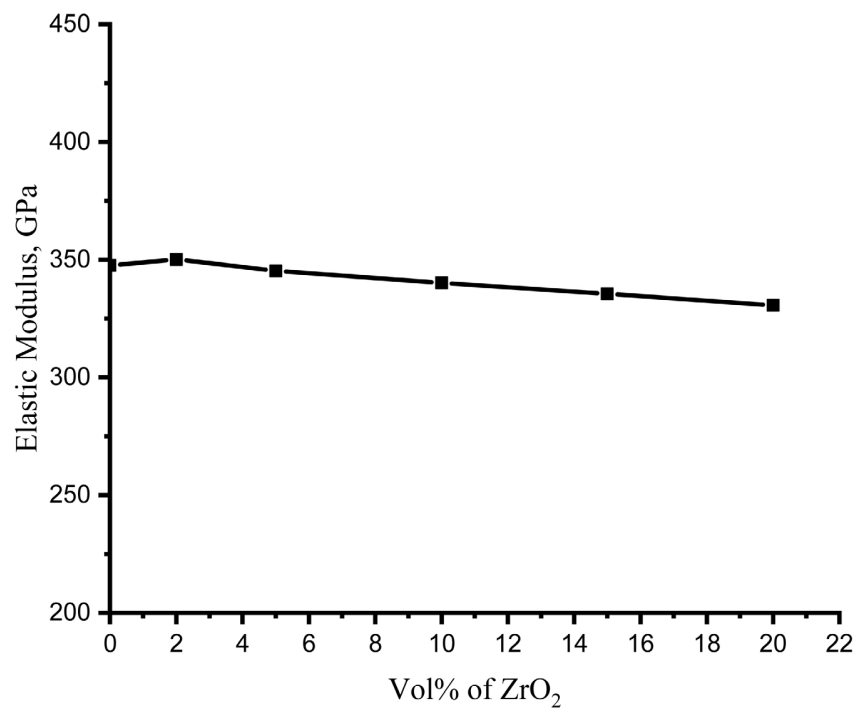

Figure 5. Effect of $\mathrm{ZrO}_{2}$ content on elastic modulus of the Alumina-Zirconia composites.

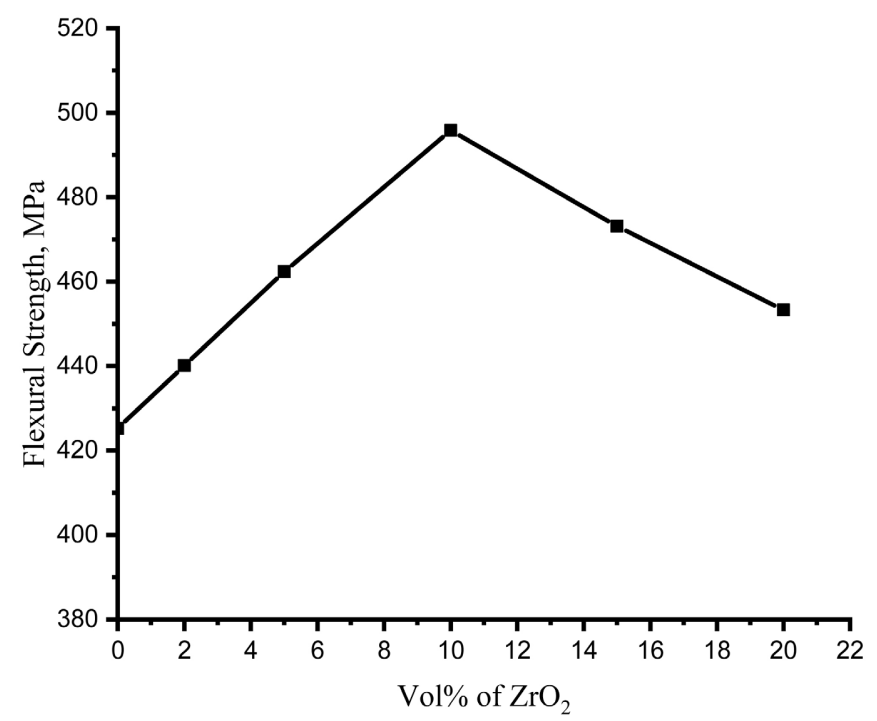

Figure 6. Effect of $\mathrm{ZrO}_{2}$ content on flexural strength of the Alumina-Zirconia composites. 


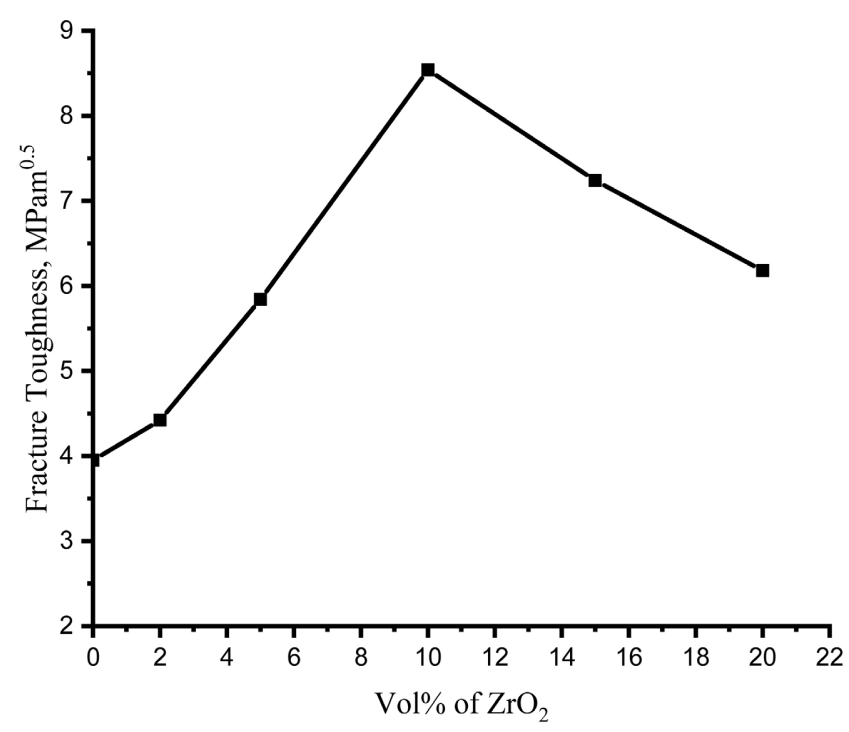

Figure 7. Effect of $\mathrm{ZrO}_{2}$ content on fracture toughness of the Alumina-Zirconia composites.

was obtained for composite containing $10 \mathrm{vol} \%$ of $\mathrm{ZrO}_{2}$. Improvement of mechanical properties of theZTA ceramics can be explained by ${ }^{\oplus}{ }^{\oplus} \mathrm{m}$ phase transformation of zirconia. This phase change increases the volume of the particle by about $3 \%-4 \%$ and produces compressive stress in the alumina matrix and act as energy barrier to further growth of any crack. The phase transformation phenomenon can be explained by X-ray diffraction of the sintered specimens (Figure 12). It is found that, the monoclinic phase $\left(\mathrm{m}-\mathrm{ZrO}_{2}\right)$ increases with the addition of $\mathrm{ZrO}_{2}$ at the same time $\mathrm{t}-\mathrm{ZrO}_{2}$ retention decreases. Up to $10 \mathrm{vol} \%$ $\mathrm{ZrO}_{2}$ addition $\mathrm{t}-\mathrm{ZrO}_{2}$ retention is obtained $70-80$ vol\% but for $15 \mathrm{vol} \%$ and 20 vol\% $\mathrm{ZrO}_{2}$ addition $\mathrm{t}-\mathrm{ZrO}_{2}$ retention decreased significantly (20 - 40 vol\%). So, due to presence of large portion of $\mathrm{m}-\mathrm{ZrO}_{2}$ and small portion of $\mathrm{t}-\mathrm{ZrO}_{2}$, the flexural strength and fracture toughness of ZTA composites containing above 10 vol\% unstabilised $\mathrm{ZrO}_{2}$ is decreased.

\subsection{X-Ray Diffraction (XRD) Analysis}

\subsubsection{Phase Analysis of Raw Materials}

The XRD patterns of the raw materials (alumina and unstabilised zirconia) for Alumina-Zirconia composites are presented in Figure 8 and Figure 9 respectively. These patterns confirm their corresponding phases' availability.

Figure 8 shows the XRD pattern of raw alumina which confirms the presence of $\alpha$-alumina (corundum) by ICDD 00-089-7717. $\alpha$-Alumina is the most stable crystalline form of alumina containing rhombohedral structure. Three major characteristic peaks were obtained from the planes (104), (113) and (116) at $2 \theta$ values are $35.11^{\circ}, 43.32^{\circ}$ and $57.48^{\circ}$, respectively. The crystallite size of alumina was obtained $23.39 \mathrm{~nm}$.

Figure 9 shows the XRD pattern of raw unstabilised zirconia which confirms the presence of monoclinic zirconia (baddeleyite) by ICDD 00-037-1484. Three 


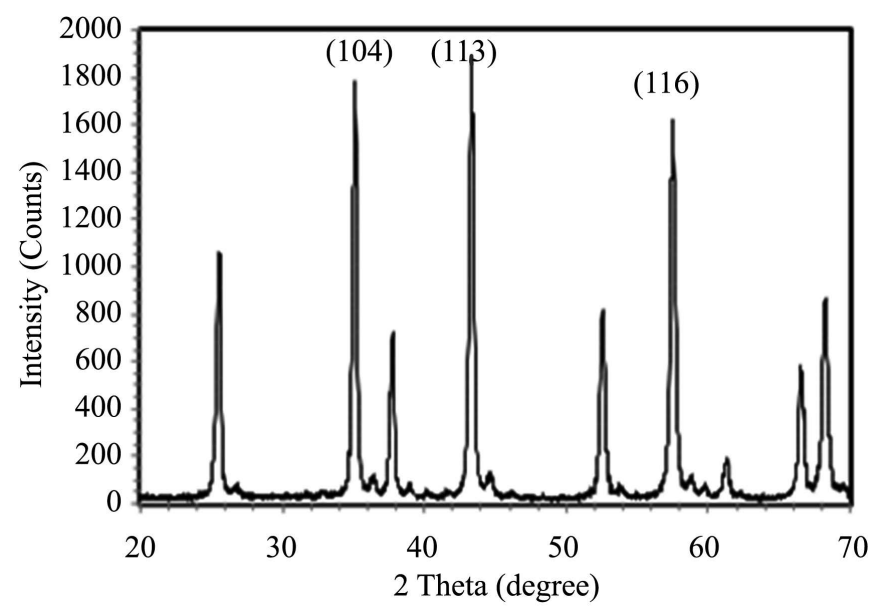

Figure 8. XRD pattern of raw alumina.

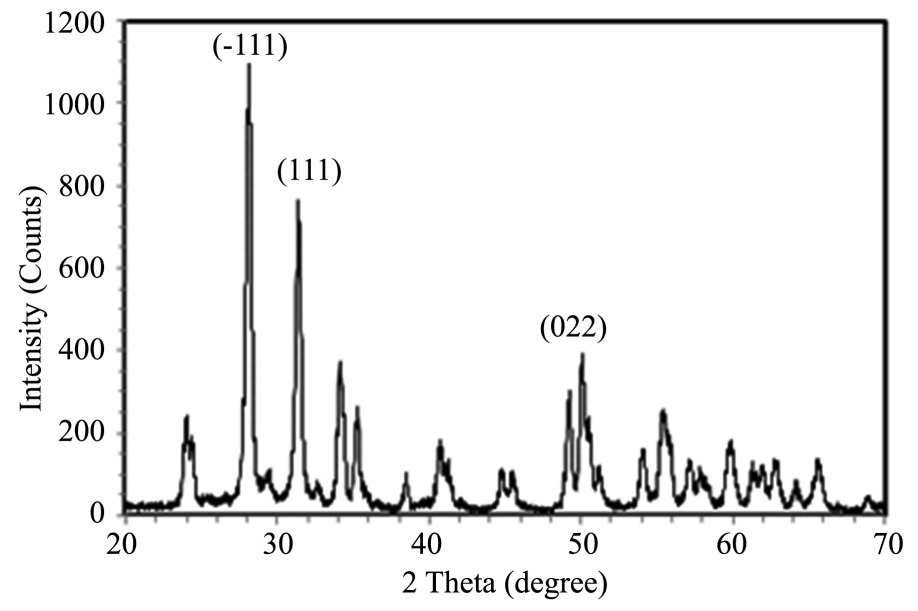

Figure 9. XRD pattern of raw unstabilised Zirconia.

main characteristics peaks were obtained from the planes (-111), (111) and (022) at $2 \theta$ values are $28.14^{\circ}, 31.41^{\circ}$ and $50.10^{\circ}$, respectively. Generally, zirconia remains in monoclinic phase at room temperature. This phase is stable up to $1170^{\circ} \mathrm{C}$. Above $1170^{\circ} \mathrm{C}$ monoclinic zirconia transforms to tetragonal zirconia and then to cubic phase at $2370^{\circ} \mathrm{C}$.

\subsubsection{Phase Analysis of Sintered Sample}

The XRD patterns of sintered pure alumina and ZTA composite containing 10 vol\% of unstabilised zirconia sintered at $1580^{\circ} \mathrm{C}$ for 2 hours are shown in Figure 10 and Figure 11 respectively which exhibits the content of different phases.

Figure 10 shows the $\mathrm{XRD}$ pattern of alumina disc sintered at $1580^{\circ} \mathrm{C}$. As like as raw alumina the phase was identified by ICDD 00-089-7717 as $\alpha$-alumina (corundum). Three major characteristic peaks were obtained at $2 \theta$ values $35.14^{\circ}$, $43.36^{\circ}$ and $57.51^{\circ}$ which are almost similar to that of the raw alumina. But the peak intensity is significantly higher than the raw alumina's peak intensity. The crystallite size of alumina obtained was $32.48 \mathrm{~nm}$ which is also larger than that of raw alumina. 


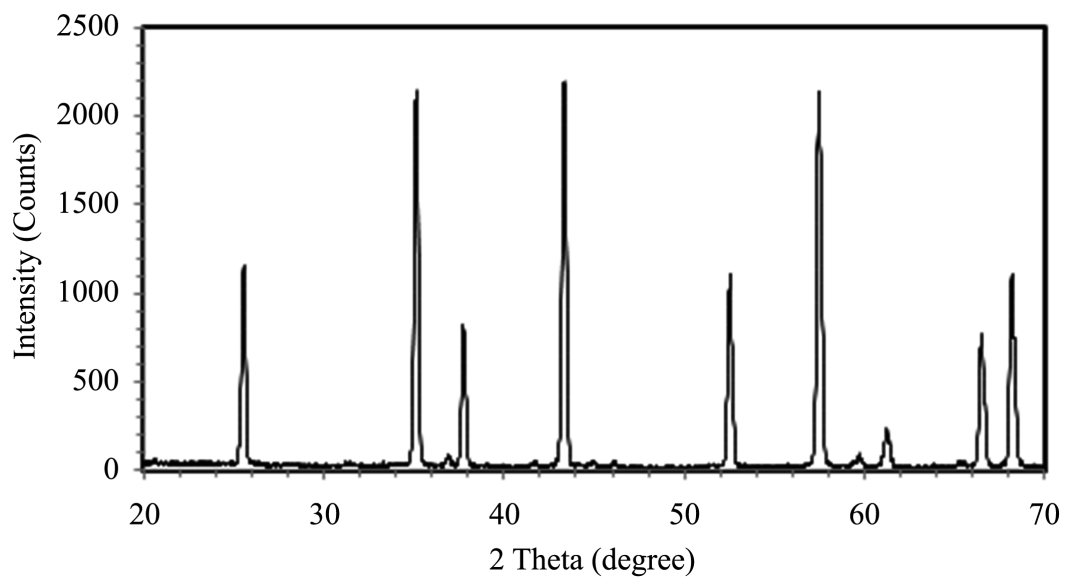

Figure 10. XRD pattern of sintered pure alumina $\left(\mathrm{Ts}=1580^{\circ} \mathrm{C}\right)$.

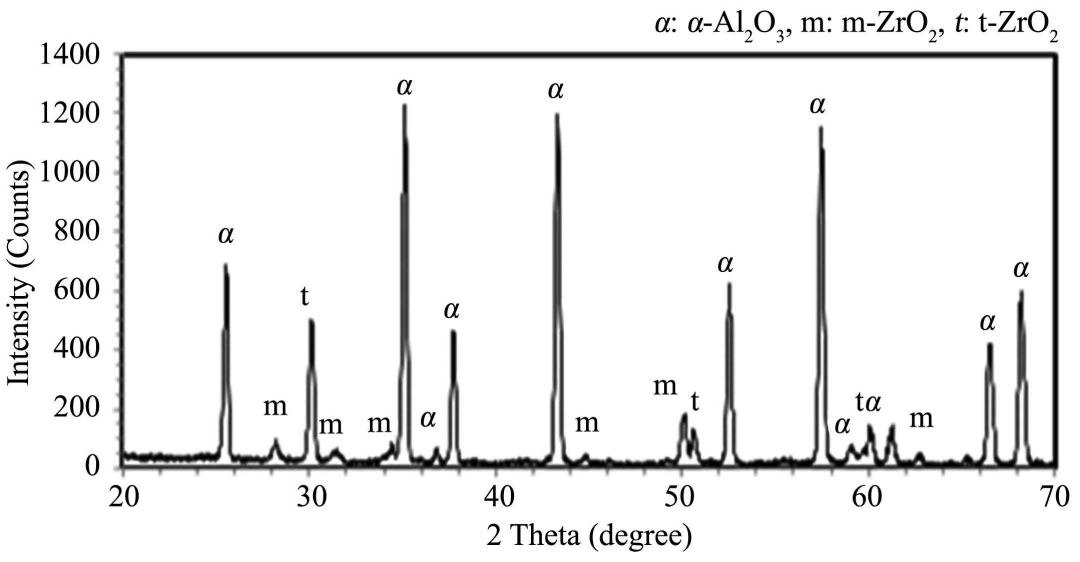

Figure 11. XRD pattern of the sintered ZTA composite containing 10 vol\% unstabilised zirconia $\left(\mathrm{Ts}=1580^{\circ} \mathrm{C}\right)$.

Figure 11 shows XRD pattern of ZTA composite containing 10 vol\% unstabilised zirconia sintered at $1580^{\circ} \mathrm{C}$ which confirms the formation of multi-phase composite. Phases of $\alpha$-alumina (corundum), monoclinic zirconia $\left(\mathrm{m}-\mathrm{ZrO}_{2}\right)$ and tetragonal zirconia $\left(\mathrm{t}-\mathrm{ZrO}_{2}\right)$ were identified by ICDD 00-089-7717, ICDD 00-037-1484 and ICDD 01-072-7115 respectively. At high temperature $\mathrm{m}-\mathrm{ZrO}_{2}$ transforms into tetragonal phase $\left(\mathrm{t}-\mathrm{ZrO}_{2}\right)$ but during cooling some of the $\mathrm{ZrO}_{2}$ phase remains in tetragonal form rather than monoclinic phase due to presence of strong alumina matrix around. The improvement in strength and toughness of Alumina-Zirconia composite results from the volume expansion and shear strain arising from tetragonal to monoclinic phase transformation of $\mathrm{ZrO}_{2}$. Each tetragonal particle release energy and expand to stable size in monoclinic form if a crack tries to propagate under stress.

\subsubsection{Variation of XRD Pattern with Zirconia Content}

The XRD patterns of ZTA ceramics containing 2, 5, 10, 15 and 20 vol\% unstabilised $\mathrm{ZrO}_{2}$ sintered at $1580^{\circ} \mathrm{C}$ for 2 hours are shown in Figure 12, which demonstrates the content of the different phases. 


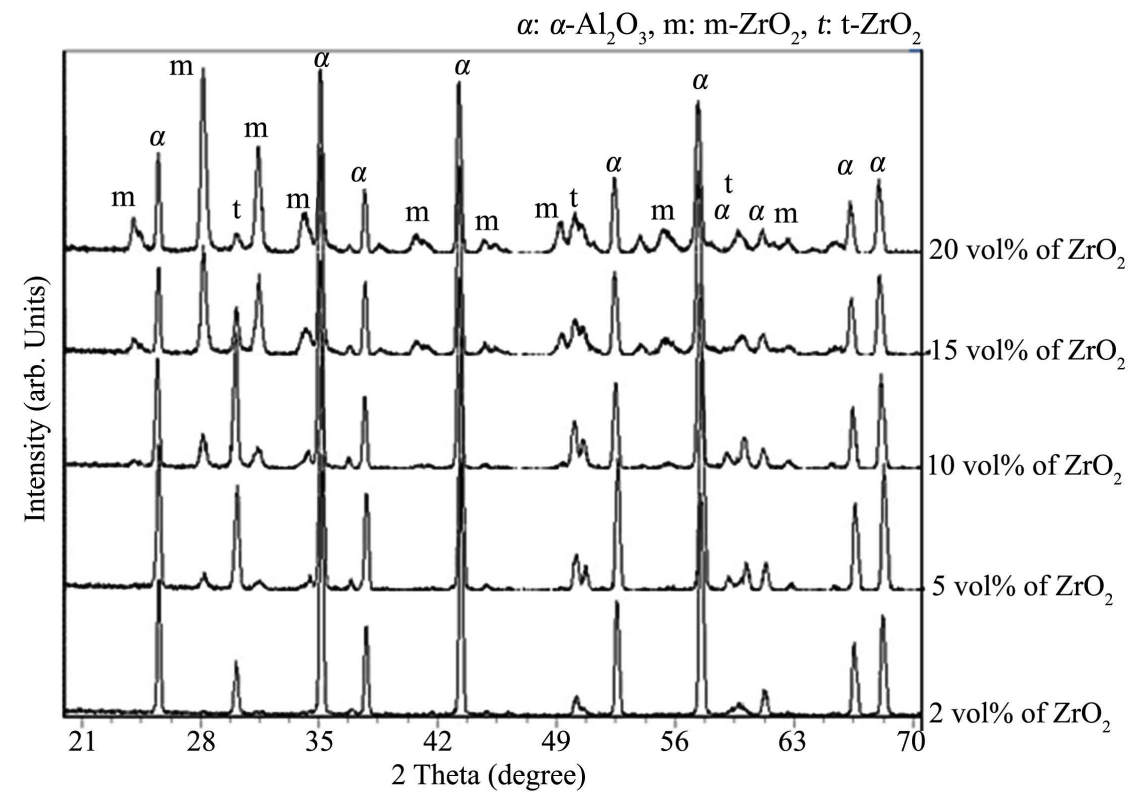

Figure 12. XRD patterns of ZTA composite containing 2 - 20 vol\% of unstabilised $\mathrm{ZrO}_{2}$ $\left(\mathrm{Ts}=1580^{\circ} \mathrm{C}\right)$.

Phases of $\alpha$-alumina (ICDD 00-089-7717)), monoclinic zirconia (00-037-1484) and tetragonal zirconia (ICDD 01-072-7115) were identified for all composites by XRD analysis. It is observed that though $\mathrm{m}-\mathrm{ZrO}_{2}$ was used for composite preparation a significant content of $\mathrm{t}-\mathrm{ZrO}_{2}$ peaks were found. The intensity of $\mathrm{t}-\mathrm{ZrO}_{2}$ initially increased with unstabilised zirconia content. Maximum peak intensity of $\mathrm{t}-\mathrm{ZrO}_{2}$ was obtained for composite containing $10 \mathrm{vol} \%$ zirconia. Above $10 \mathrm{vol} \%$ zirconia peak intensity of $\mathrm{t}-\mathrm{ZrO}_{2}$ decreased and minimum intensity was obtained from composites containing $20 \mathrm{vol} \%$ zirconia. But intensity of $\mathrm{m}-\mathrm{ZrO}_{2}$ continuously increased with zirconia content. Low content of $\mathrm{ZrO}_{2}$ and high percentage of $\mathrm{Al}_{2} \mathrm{O}_{3}$ is favorable to retain $\mathrm{t}-\mathrm{ZrO}_{2}$ due to the presence of more alumina matrix. As sufficient alumina was available to retain the $\mathrm{ZrO}_{2}$ in tetragonal form, the intensity of $\mathrm{t}-\mathrm{ZrO}_{2}$ increased up to the $10 \mathrm{vol} \%$ zirconia addition. Above $10 \mathrm{vol} \%$ zirconia addition, sufficient amount of alumina was not available to retain the $\mathrm{ZrO}_{2}$ in tetragonal form. As a result, intensity of $\mathrm{t}-\mathrm{ZrO}_{2}$ decreased with above $10 \mathrm{vol} \%$ zirconia addition. But the intensity of $\mathrm{m}-\mathrm{ZrO}_{2}$ increased continuously. Mixture of both tetragonal and monoclinic $\mathrm{ZrO}_{2}$ phases imparts to increase strength and toughness of the ZTA ceramics. The extent of toughening achieved in the composites depend on the particle size of $\mathrm{Al}_{2} \mathrm{O}_{3}$ and $\mathrm{ZrO}_{2}$, volume fraction of $\mathrm{ZrO}_{2}$ retained in the metastable tetragonal phase as well as on the relative distribution of $\mathrm{Al}_{2} \mathrm{O}_{3}$ and $\mathrm{ZrO}_{2}$ in the matrix [28]. Finer particle size of both $\mathrm{Al}_{2} \mathrm{O}_{3}$ and $\mathrm{ZrO}_{2}$ will not only enhance the uniform distribution of $\mathrm{Al}_{2} \mathrm{O}_{3}$ and $\mathrm{ZrO}_{2}$ particles, but also increases the possibility of $\mathrm{ZrO}_{2}$ being retained as metastable tetragonal phase [29].

\subsection{4. $\mathrm{t}-\mathrm{ZrO}_{2}$ Retention}

In the present study, ZTA ceramic composite was fabricated using unstabilized- 
$\mathrm{ZrO}_{2}$ with small amount of sintering aid. It is noticed from the Figure 12 that, the $\mathrm{ZrO}_{2}$ particles are mainly of tetragonal phase embedded in corundum $\left(\alpha-\mathrm{Al}_{2} \mathrm{O}_{3}\right)$. The main peaks oft- $\mathrm{ZrO}_{2}$ are sharp and high. From Figure 13 it has been shown that, the $\mathrm{t}-\mathrm{ZrO}_{2}$ phase retention is almost $79 \%$ for the composite containing $5 \mathrm{vol} \% \mathrm{ZrO}_{2}$ which exhibits their good stability. However, the $\mathrm{t}-\mathrm{ZrO}_{2}$ fraction decreases and $\mathrm{m}-\mathrm{ZrO}_{2}$ phase increases with increasing $\mathrm{ZrO}_{2}$ content and it reduced to $10.4 \%$ for the composite containing $20 \mathrm{vol} \% \mathrm{ZrO}_{2}$. It is confirmed that, tetragonal phase retained at room temperature as a metastable phase due to presence of hard alumina matrix around, and this phase plays the principal role for the improvement of fracture toughness by transformation toughening mechanism.

Previous research work shows that, fraction of tetragonal phase increases when the quantity of $\mathrm{ZrO}_{2}$ decreases in the composite material (30 vol\% of tetragonal phase for $5 \mathrm{vol} \% \mathrm{ZrO}_{2}$, but only $5 \%$ of tetragonal phase for $20 \mathrm{vol} \%$ of $\mathrm{ZrO}_{2}$ ) [30] [31]. If the tetragonal phase is overstabilized, the stress required for transformation in the high stress region around a crack tip may be higher than the fracture stress. As a result, the flexural strength of the composite will become low. In this study, ZTA composite consists of a mixture of tetragonal and monoclinic zirconia where tetragonal phase is not overstabilized.

\subsection{Scanning Electron Microscopic (SEM) Analysis}

Figures 14(a)-(c) show the SEM micrographs of sintered pure alumina and ZTA ceramic composites. Figure 14(a) showed the dark large grain size of alumina and Figure 14(b) and Figure 14(c) showed that, comparatively dark (gray contrast) and large grains are $\mathrm{Al}_{2} \mathrm{O}_{3}$ whereas bright (white contrast) and small grains are $\mathrm{ZrO}_{2}$. Both $\mathrm{Al}_{2} \mathrm{O}_{3}$ and $\mathrm{ZrO}_{2}$ grains are fairly homogeneous in each composition and $\mathrm{ZrO}_{2}$ grains are distributed throughout the alumina matrix.

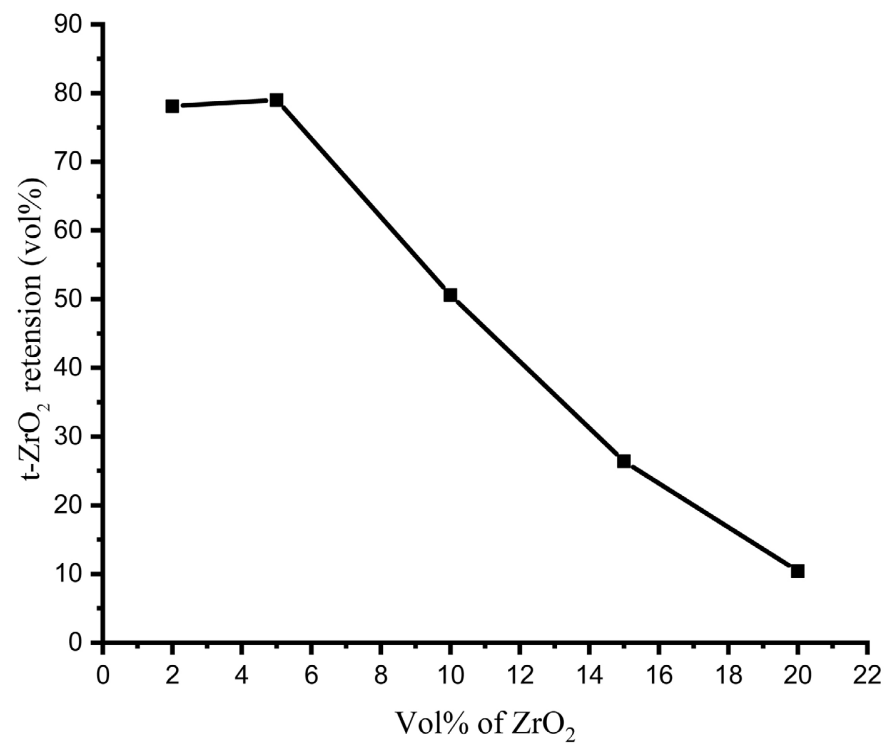

Figure 13. Retention of $\mathrm{ZrO}_{2}$ as a function of Zirconia content. 


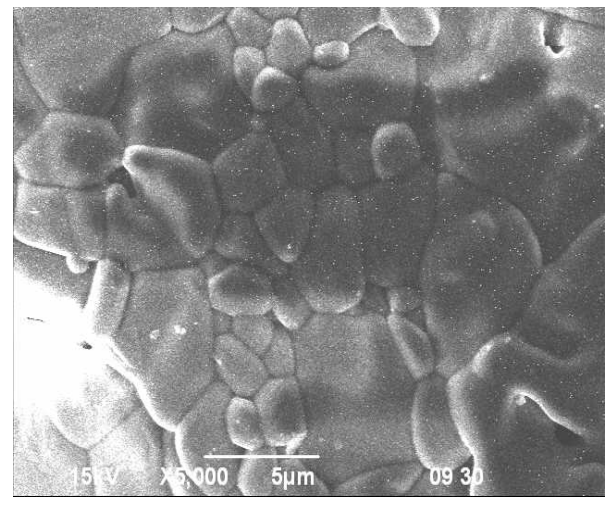

(a)

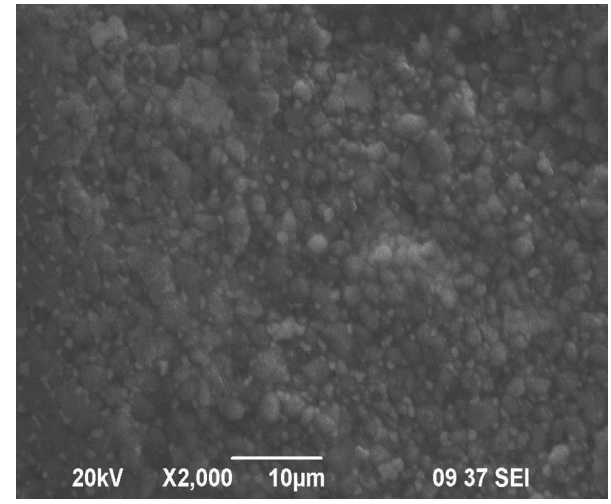

(b)

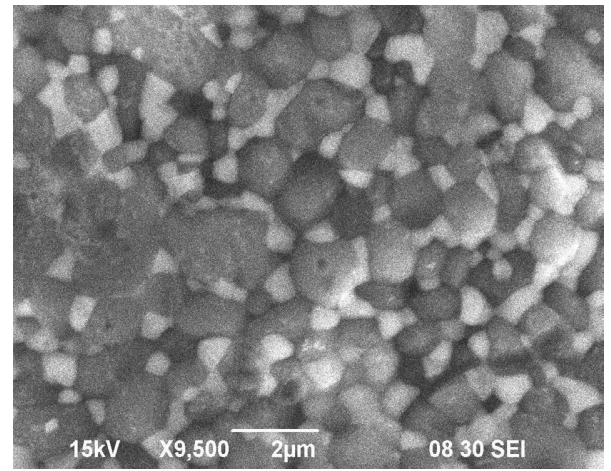

(c)

Figure 14. (a) Microstructure of sintered pure aluminadisc; (b) Microstructure of ZTA composite containing $90 \% \mathrm{Al}_{2} \mathrm{O}_{3}$ and $10 \%$ unstabilised $\mathrm{ZrO}_{2}$; (c) Microstructure of $\mathrm{AZ}$ composite containing $80 \% \mathrm{Al}_{2} \mathrm{O}_{3}$ and $20 \%$ unstabilised $\mathrm{ZrO}_{2}$.

The addition of $\mathrm{ZrO}_{2}$ creates a pinning effect around the alumina grain and hindered the grain growth of alumina during sintering, even for the lowest zirconia content. The addition up to $10 \mathrm{vol} \% \mathrm{ZrO}_{2}$ prevents grain growth of alumina without formation of $\mathrm{ZrO}_{2}$ agglomeration. But in case of 20 vol\% of $\mathrm{ZrO}_{2}$ content, the premature agglomeration of $\mathrm{ZrO}_{2}$ was observed in the composite. Figure 14(b) and Figure 14(c) show that the increase in $\mathrm{ZrO}_{2}$ content increases $\mathrm{ZrO}_{2}$ grain and decreases the grain size of alumina.

The present study also shows that, $\mathrm{ZrO}_{2}$ grains are located at the grain boun- 
daries (triple points) of alumina. This occupation of the triple points is increased from lower to higher content of $\mathrm{ZrO}_{2}$ and almost fully occupied for more than 10 vol\% $\mathrm{ZrO}_{2}$ content. This result conforms the result that was published in previously [32].

\subsection{Grain Size Analysis}

Figure 15 and Figure 16 show the variation of grain size of alumina and zirconia in sintered ZTA composites with respect to zirconia content.

From Figure 15 it is observed that grain size of $\mathrm{Al}_{2} \mathrm{O}_{3}$ decreased significantly when a small amount of $\mathrm{ZrO}_{2}(5 \mathrm{vol} \%)$ is added with alumina. Further addition of $\mathrm{ZrO}_{2}$ led to decrease in alumina grain size slowly and linearly. In the present work maximum average grain size was obtained $6.25 \mu \mathrm{m}$ for pure alumina. For 5

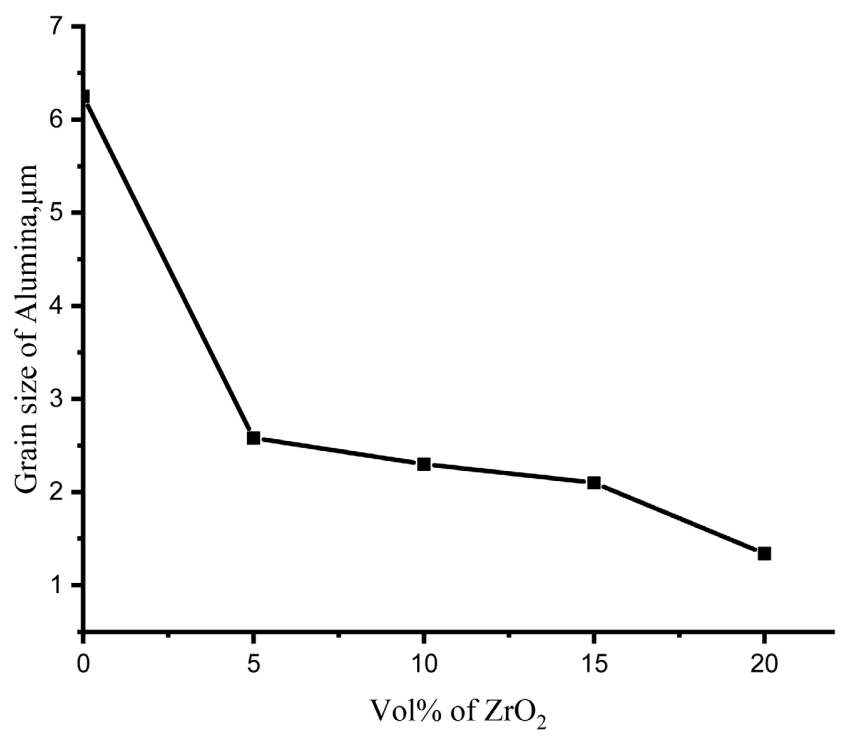

Figure 15. Effect of $\mathrm{ZrO}_{2}$ content on grain size of alumina in ZTA composites.

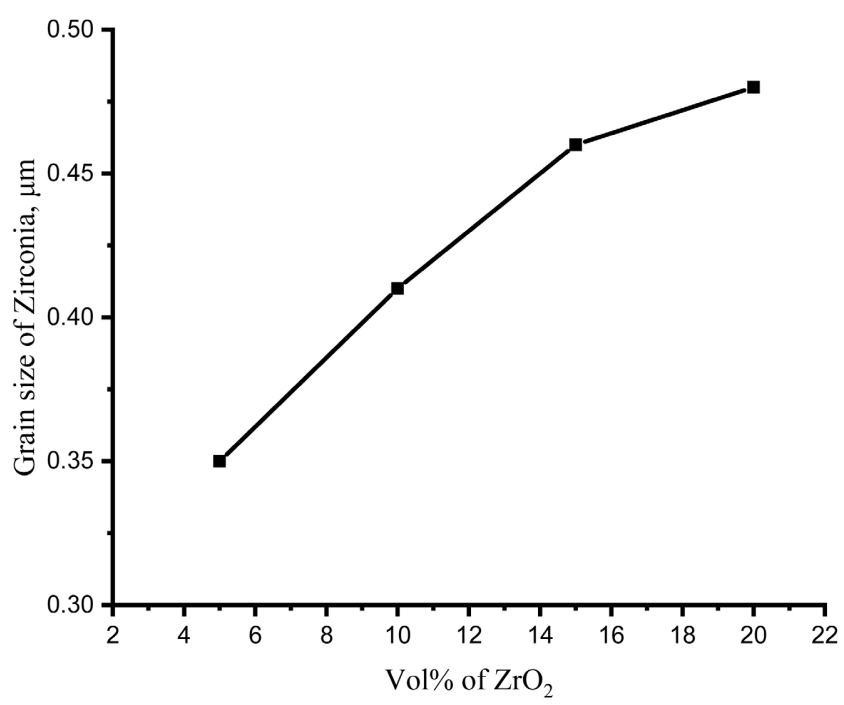

Figure 16. Effect of $\mathrm{ZrO}_{2}$ content on Zirconia grain size in ZTA composites. 
vol\% of zirconia addition alumina grain size decreased to $2.58 \mu \mathrm{m}$. Minimum grain size of alumina was obtained $1.34 \mu \mathrm{m}$ for Alumina-Zirconia composite containing $20 \mathrm{vol} \%$ of zirconia. On the other hand, grain size of zirconia in Alumina-Zirconia composite increased linearly with zirconia content (Figure 16). In the present study minimum and maximum grain size of zirconia was obtained $0.35 \mu \mathrm{m}$ and $0.48 \mu \mathrm{m}$ for ZTA composite containing $5 \mathrm{vol} \%$ and $20 \mathrm{vol} \%$ $\mathrm{ZrO}_{2}$ respectively. The present results are harmonious with some previous research [33]. The increase in density of Alumina-Zirconia composite may due to the enhanced compaction with zirconia addition as well as the role of zirconia as a grain refiner to reducing the grain size of alumina.

\section{Conclusion}

ZTA composites containing 0 - 20 vol\% unstabilized zirconia have been fabricated and $99.2 \%$ densification can be achieved at $1580^{\circ} \mathrm{C}$. Homogeneous zirconia particles were dispersed in the alumina matrix and abnormal grain growth of the matrix was not observed. For better mechanical properties, the optimum amount of $\mathrm{ZrO}_{2}$ was found to be 10 vol\%. The flexural strength and fracture toughness increase up to this amount of $\mathrm{ZrO}_{2}$ addition. Microhardness and elastic modulus follow the inverse relationship with $\mathrm{ZrO}_{2}$ content. Maximum microhardness (17.35 $\mathrm{GPa}$ ) and elastic modulus were found for the composite containing $5 \mathrm{vol} \%$ and $2 \mathrm{vol} \%$ of $\mathrm{ZrO}_{2}$ respectively. Further addition of $\mathrm{ZrO}_{2}$ can degrade the mechanical properties due to grain coarsening. The size of the alumina and intergranular zirconia grains predominantly influences the properties of the ceramic composites. It is hoped that the present study will guide further experimental work in Alumina-Zirconia system, especially for unstabilized zirconia performance.

\section{Conflicts of Interest}

The authors declare no conflicts of interest regarding the publication of this paper.

\section{References}

[1] Ashby, M.M. and Jones, D.R.H. (2012) Chapter 1-Engineering Materials and Their Properties. In: Engineering Materials 1: An Introduction to Properties, Applications and Design, Butterworth-Heinemann, Burlington, MA. https://doi.org/10.1016/B978-0-08-096665-6.00001-5

[2] Fischer, H. and Marx, R. (2002) Fracture Toughness of Dental Ceramics: Comparison of Bending and Indentation Method. Dental Materials, 18, 12-19. https://doi.org/10.1016/S0109-5641(01)00005-7

[3] Yoshimura, M. (1988) Phase Stability of Zirconia. American Ceramic Society Bulletin, 67, 1950-1955.

[4] Mills, H. and Blackburn, S. (2000) Zirconia Toughened Aluminas by Hydro-Thermal Processing. Journal of the European Ceramic Society, 20, 1085-1090. https://doi.org/10.1016/S0955-2219(99)00274-5 
[5] Bleier, A., Becher, P.F., Alexander, K.B. and Westmoreland, C.G. (1991) Effects of $\mathrm{pH}$ and Particle Size on the Processing of and the Development of Microstructure in Alumina-Zirconia Composites. Journal of the American Ceramic Society, 74, 3100-3111. https://doi.org/10.1111/j.1151-2916.1991.tb04307.x

[6] Suzuki, T.S., Sakka, Y., Nakano, K. and Hiraga, K. (1998) Effects of Ultrasonication on Colloidal Dispersion of $\mathrm{Al}_{2} \mathrm{O}_{3}$ and $\mathrm{ZrO}_{2}$ Powders in $\mathrm{pH}$ Controlled Suspension. Materials Transactions, JIM, 39, 689-692. https://doi.org/10.2320/matertrans1989.39.689

[7] Garvie, R.C., Hannik, R.H. and Pascoe, R.T. (1975) Ceramic Steel? Nature, 258, 703-704. https://doi.org/10.1038/258703a0

[8] Cannon, W.R. (1989) Transformation Toughened Ceramics for Structural Applications. Treatise on Materials Science \& Technology, 29, 195-228. https://doi.org/10.1016/B978-0-12-341829-6.50010-4

[9] Wang, J. and Stevens, R. (1989) Zirconia-Toughened Alumina (ZTA) Ceramics. Journal of Materials Science, 24, 3421-3440. https://doi.org/10.1007/BF02385721

[10] Claussen, N. (1976) Fracture Toughness of $\mathrm{Al}_{2} \mathrm{O}_{3}$ with an Unstabilized $\mathrm{ZrO}_{2}$ Dispersed Phase. Journal of the American Ceramic Society, 59, 49-51. https://doi.org/10.1111/j.1151-2916.1976.tb09386.x

[11] Becher, P.F. (1991) Advances in the Design of Toughened Ceramics. Journal of the Ceramic Society of Japan, 99, 993-1001. https://doi.org/10.2109/jcersj.99.993

[12] Heuer, A.H., Lange, F.F., Swain, M.V. and Evans, A.G. (1986) Transformation Toughening: An Overview. Journal of the American Ceramic Society, 69, i-iv. https://doi.org/10.1111/j.1151-2916.1986.tb07400.x

[13] Bleier, A., Becher, P.F., Alexander, K.B. and Westmoreland, C.G. (1992) Effect of Aqueous Processing Conditions on the Microstructure and Transformation Behavior in $\mathrm{Al}_{2} \mathrm{O}_{3}-\mathrm{ZrO}_{2}\left(\mathrm{CeO}_{2}\right)$ Composites. Journal of the American Ceramic Society, 75, 2649-2658. https://doi.org/10.1111/j.1151-2916.1992.tb05484.x

[14] Prakash, J. (2011) Alumina-Zirconia Composite by Slurry Method. J, 3, 1359-1367.

[15] de Sá e Benevides de Moraes, M.C.C., Elias, C.N., Duailibi Filho, J. and de Oliveira, L.G. (2004) Mechanical Properties of Alumina-Zirconia Composites for Ceramic Abutments. Materials Research, 7, 643-649. https://doi.org/10.1590/S1516-14392004000400021

[16] Tuan, W.H., Chen, R.Z., Wang, T.C., Cheng, C.H. and Kuo, P.S. (2002) Mechanical Properties of $\mathrm{Al}_{2} \mathrm{O}_{3} / \mathrm{ZrO}_{2}$ Composites. Journal of the European Ceramic Society, 22, 2827-2833. https://doi.org/10.1016/S0955-2219(02)00043-2

[17] Abbas, S., Maleksaeedi, S., Kolos, E. and Ruys, A.J. (2015) Processing and Properties of Zirconia-Toughened Alumina Prepared by Gelcasting. Materials, 8, 4344-4362. https://doi.org/10.3390/ma8074344

[18] Yu, Y.D., Zheng, Y.T., Liu, X.D., Yuan, Y.C., Yu, W.J. and He, X.D. (2021) Microstructure Evolution of $\mathrm{YSZ} / \mathrm{Al}_{2} \mathrm{O}_{3}$ Supersaturated Solid Solution. Applied Surface Science, 549, Article ID: 149260. https://doi.org/10.1016/j.apsusc.2021.149260

[19] Pabst, W., Tichá, G., Gregorová, E. and Týnová, E. (2005) Effective Elastic Properties of Alumina-Zirconia Composite Ceramics Part 5. Tensile Modulus of Alumina-Zirconia Composite Ceramics. Ceramics-Silikaty, 49, 77-85.

[20] Hossen, M.M., Gafur, M.A. and Hakim, A.K.M.A. (2014) Structural and Mechanical Properties of Zirconia Toughened Alumina (ZTA) Composites. International journal of Engineering Research and Technology, 3, 2128-2134.

[21] Anstis, G.R., Chantikul, P., Lawn, B.R. and Marshall, D.B. (1981) A Critical Evalua- 
tion of Indentation Techniques for Measuring Fracture Toughness: I, Direct Crack Measurements. Journal of the American Ceramic Society, 64, 533-538. https://doi.org/10.1111/j.1151-2916.1981.tb10320.x

[22] Rao, P.G., Iwasa, M., Tanaka, T., Kondoh, I. and Inoue, T. (2003) Preparation and Mechanical Properties of $\mathrm{Al}_{2} \mathrm{O}_{3}-15 \mathrm{wt}$. $\% \mathrm{ZrO}_{2}$ Composites. Scripta Materialia, 48, 437-441. https://doi.org/10.1016/S1359-6462(02)00440-2

[23] Garvie, R.C. and Nicholson, P.S. (1972) Phase Analysis in Zirconia Systems. Journal of the American Ceramic Society, 55, 303-305. https://doi.org/10.1111/j.1151-2916.1972.tb11290.x

[24] Wu, Y., Bandyopadhyay, A. and Bose, S. (2004) Processing of Alumina and Zirconia Nano-Powders and Compacts. Materials Science and Engineering: A, 380, 349-355. https://doi.org/10.1016/j.msea.2004.04.036

[25] Hori, S., Yoshimura, M., Sōmiya, S. and Kaji, H. (1984) Change of Tetragonal $\mathrm{ZrO}_{2}$ content in $\mathrm{ZrO}_{2}$-Toughened $\mathrm{Al}_{2} \mathrm{O}_{3}$ by Hot Isostatic Pressing. Journal of Materials Science Letters, 3, 242-244. https://doi.org/10.1007/BF00726804

[26] Tan, K.S., Hing, P. and Ramalingam, P. (1997) The Elastic Moduli and Diametrical Compressive Fracture Stress of $\mathrm{Al}_{2} \mathrm{O}_{3}-\mathrm{ZrO}_{2}$ Ceramics. Journal of Physics D: Applied Physics, 30, 1029-1037. https://doi.org/10.1088/0022-3727/30/6/017

[27] Eichler, J., Eisele, U. and Rödel, J. (2004) Mechanical Properties of Monoclinic Zirconia. Journal of the American Ceramic Society, 87, 1401-1403. https://doi.org/10.1111/j.1151-2916.2004.tb07748.x

[28] Garvie, R.C. (1965) The Occurrence of Metastable Tetragonal Zirconia as a Crystallite Size Effect. The Journal of Physical Chemistry, 69, 1238-1243. https://doi.org/10.1021/j100888a024

[29] Heuer, A.H., Claussen, N., Kriven, W.M. and Ruhle, M. (1982) Stability of Tetragonal $\mathrm{ZrO}_{2}$ Particles in Ceramic Matrices. Journal of the American Ceramic Society, 65, 642-650. https://doi.org/10.1111/j.1151-2916.1982.tb09946.x

[30] Menger, K. and Ford, L.R. (1944) Discussions and Notes. The American Mathematical Monthly, 51, 392-398. https://doi.org/10.1080/00029890.1944.11999120

[31] Claussen, N. (1978) Stress-Induced Transformation of Tetragonal $\mathrm{ZrO}_{2}$, Particles in Ceramic Matrices. Journal of the American Ceramic Society, 61, 85-86. https://doi.org/10.1111/j.1151-2916.1978.tb09237.x

[32] Biamino, S., Fino, P., Pavese, M. and Badini, C. (2006) Alumina-Zirconia-Yttria Nanocomposites Prepared by Solution Combustion Synthesis. Ceramics International, 32, 509-513. https://doi.org/10.1016/j.ceramint.2005.04.004

[33] Casellas, D., Ràfols, I., Llanes, L. and Anglada, M. (1999) Fracture Toughness of Zirconia-Alumina Composites. International Journal of Refractory Metals and Hard Materials, 17, 11-20. https://doi.org/10.1016/S0263-4368(98)00064-X 